\title{
Prehospital management and identification of sepsis by emergency medical services: a systematic review
}

\author{
Daniel Lane, ${ }^{1,2,3}$ Robbie I Ichelson, ${ }^{4}$ Ian R Drennan, ${ }^{2,3}$ Damon C Scales ${ }^{5,6}$
}

\begin{abstract}
- Additional material is published online only. To view please visit the journal online (http://dx.doi.org/10.1136/ emermed-2015-205261).

${ }^{1}$ Alberta Health Services, Emergency Medical Services, Calgary Zone EMS Headquarters, Calgary, Alberta, Canada

${ }^{2}$ Rescu, Li Ka Shing Knowledge Institute, St Michael's Hospital, Ontario, Canada

${ }^{3}$ Faculty of Medicine, Institute of Medical Science, University of Toronto, Ontario, Canada

${ }^{4}$ University of Ontario Institute of Technology, Ontario,

Canada

${ }^{5}$ Department of Critical Care Medicine, Sunnybrook Health Sciences Centre, Ontario, Canada

${ }^{6}$ Interdepartmental Division of Critical Care, University of Toronto, Ontario, Canada
\end{abstract}

\section{Correspondence to} Daniel Lane, Alberta Health Services, Emergency Medical Services, Suite 100, Calgary Zone EMS Headquarters, 3705 35 Street NE, Calgary, Alberta, Canada T1Y 6C2:

danjlane@me.com

Received 24 July 2015 Revised 8 January 2016 Accepted 17 January 2016 Published Online First 10 February 2016

\begin{abstract}
Objective To identify studies describing the accuracy of prehospital sepsis identification and to summarise results of studies of prehospital management of patients with sepsis, severe sepsis or septic shock.
\end{abstract}

Methods We conducted a systematic review to retrieve studies that evaluated the prehospital identification or treatment of patients with sepsis by emergency medical services (EMS). Two authors extracted data describing the study characteristics, incidence of sepsis among EMS-transported patients, criteria used to identify sepsis and specific treatments provided to patients with sepsis. When possible, we calculated the sensitivity and specificity of EMS provider diagnosis of sepsis.

Results Our search identified no randomised controlled trials and 16 cohort studies. Eight studies described the identification of sepsis, seven described prehospital management or treatment of sepsis and one described both. The most common approach to the identification of sepsis involved applying systemic inflammatory response syndrome criteria or a combination of vital signs, which had sensitivity ranging from 0.43 to 0.86 when used alone or combined with provider impression. Only four studies collected information required to calculate specificity (0.47-0.87). Meta-analysis was not performed owing to significant heterogeneity and an overall low quality of evidence. A few studies described prehospital sepsis treatment-most commonly intravenous fluid resuscitation.

Conclusions The evidence suggests that identification of sepsis in the prehospital setting by EMS providers is carried out with varied success, depending on the strategy used; however, high-quality studies are lacking. Relying on provider impression alone had poor sensitivity, but some moderate-quality evidence supporting structured screening for sepsis with vital signs criteria demonstrated modest sensitivity and specificity. Additional research to improve diagnostic accuracy and explore improvements in EMS management is needed.

\section{INTRODUCTION}

Severe sepsis is associated with a high morbidity and mortality rate and remains the most common cause of death among critically ill patients. ${ }^{1}$ To manage this disease effectively, early recognition and prompt treatment are recommended. ${ }^{2}$ Although the use of a protocol for treatment of sepsis has recently been questioned, ${ }^{3}$ it is widely accepted that early recognition and intervention are essential to achieving good patient outcomes. ${ }^{4}$

In modern healthcare systems, emergency medical services (EMS) practitioners are often the first healthcare providers to attend to patients with life-threatening injuries and illnesses, including

\section{Key messages}

What is already known on this subject?

- Patients with severe sepsis and septic shock have a high risk of death.

- Emergency medical services (EMS) practitioners are the first healthcare contact for many of these patients, and can provide early identification and intervention.

- The knowledge required for EMS identification or treatment of sepsis has not been previously described.

\section{What might this study add?}

- This study provides a summary of the available evidence, examining the role that EMS practitioners might play in identifying sepsis in the field and providing early treatments.

- The evidence suggests that these clinicians can identify patients with sepsis with modest sensitivity and specificity and that additional research to improve diagnostic accuracy is needed.

- Fluid resuscitation was the most commonly described treatment provided by EMS but the effect on patient outcomes requires further study.

sepsis. EMS practitioners can provide a variety of critical interventions before the patient arrives at hospital. For many time-sensitive health problems, including acute myocardial infarction, trauma, stroke and cardiac arrest, these critical interventions have been shown to improve patients' chances of survival and improve outcomes. ${ }^{5-7}$ More patients with sepsis are transported by EMS to hospital than patients with acute myocardial infarction or stroke and almost half of all patients admitted to hospital with severe sepsis are brought to the emergency department (ED) by the EMS. ${ }^{8}$ This suggests that EMS practitioners might also be able to provide time-sensitive treatments for patients with severe sepsis. However, targeted evidence-based treatments of sepsis have seldom been adopted within EMS systems. ${ }^{9}$

Despite this opportunity for early recognition and intervention before arriving at the ED, little is known about practice and research in this area. A comprehensive summary would allow researchers to have a better understanding of the current state of knowledge and areas where further study is required. Therefore, we conducted a systematic review of the literature to identify studies describing the accuracy of prehospital sepsis identification 
and to summarise results of studies of prehospital management (ie, patient characteristics or interventions) for patients with severe sepsis or septic shock.

\section{METHODS}

We conducted a comprehensive literature search of the Medline, EMBASE, CINAHL and Cochrane Library databases for all available years until October 2015 to identify studies describing the accuracy of prehospital sepsis identification or potential prehospital sepsis treatments. We combined the following search terms with appropriate synonyms and wildcards: (1) sepsis ("septic", "infection") and (2) Emergency Medical Services ("paramedic", "out-of-hospital", or "prehospital") (see online supplementary data). Two authors (DL and RII) independently reviewed the titles and abstracts to identify all relevant English original research studies. Any study flagged by either author as potentially relevant underwent full text review and disagreements were resolved by consensus. We also conducted an independent hand search of the bibliography of all included studies to identify any potentially relevant studies not captured in our search. All original research studies that described the identification or treatment of patients with sepsis in the prehospital setting were included. Studies that were only reported as abstracts were not included.

Retrieved studies were sorted into two groups: studies that examined identification of patients with sepsis by EMS practitioners or those describing prehospital management or treatment of patients with sepsis. We abstracted data describing general study characteristics, incidence of sepsis among EMS-transported patients, tools or characteristics used to identify sepsis and specific management or treatments provided to patients with sepsis. When possible, we calculated the sensitivity and specificity of EMS practitioner diagnosis of sepsis using the available data. The quality of included studies was assessed using the Grading of Recommendations Assessment, Development and Evaluation (GRADE) methodology. ${ }^{10}$

\section{RESULTS}

Our search identified 3885 unique publications, of which 16 were retained after a full-text review. Of the included studies, eight described the identification of sepsis in the prehospital setting, seven described prehospital management or treatment of patients with sepsis and one described both (figure 1). Agreement between reviewers was moderate $(\kappa=0.56)$ at the abstract review stage but excellent at the full-text review stage for final article inclusion $(\kappa=1.0)$.

Characteristics of the included studies are summarised in table 1 . Studies were primarily conducted in single centres $(n=12 / 16)$ and in the USA $(n=12 / 16)$. Identified studies used a cohort study design $(n=16 / 16)$ with data collected using chart review in the majority $(n=13 / 16)$.

\section{Quality of evidence}

Among studies evaluating prehospital identification of sepsis, the overall quality of evidence was low for studies using provider impression alone for identification and moderate for studies using vital signs (table 1). The quality of evidence for studies describing the management of patients by EMS varied considerably (table 1). A common limitation of included studies was a risk of selection bias due to retrospective selection of patients based on the in-hospital diagnosis of sepsis and a lack of blinded comparison of the EMS providers' identification of patients with sepsis and the reference standard that was used for diagnosing sepsis. Combining results across studies using

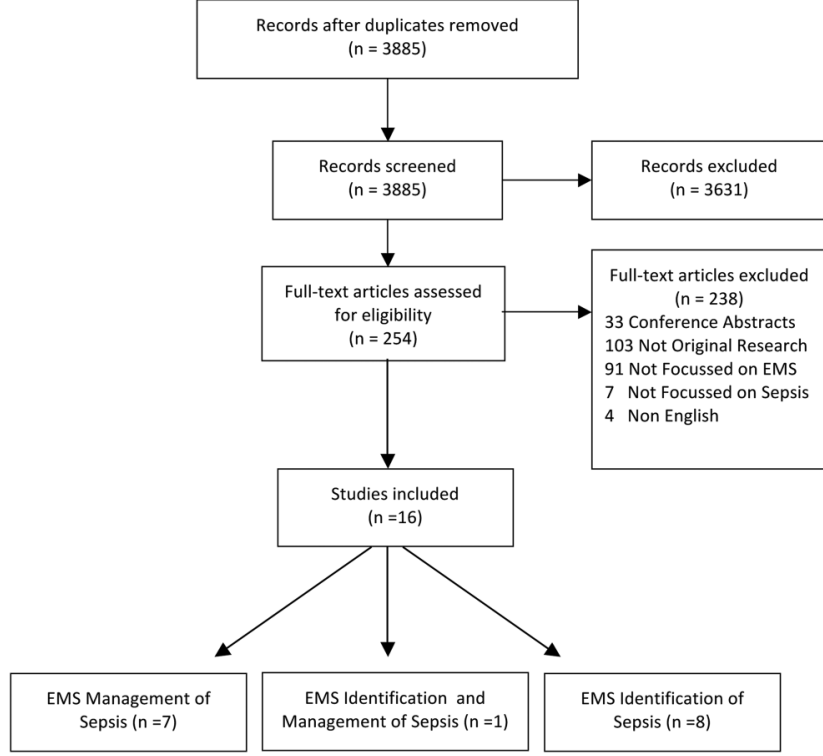

Figure 1 Study flow diagram.

meta-analysis (ie, for incidence, sensitivity and specificity) was therefore deemed inappropriate based on the overall low quality of evidence and high degree of heterogeneity.

\section{Incidence of sepsis}

Overall, the incidence of sepsis ranged from 1\% to $8 \%$ among patients transported by EMS (table 1). The severity of disease among this cohort of transported patients with sepsis was high, with the proportion who were subsequently admitted to hospital ranging between $40 \%$ and $60 \%$ ( $n=3$ studies). ${ }^{8} 1112$

\section{Identification of sepsis}

Abnormal vital signs were the most commonly applied criteria for identifying patients with sepsis, with four of nine studies considering vital sign abnormalities commonly used within the framework of severe inflammatory response syndrome (SIRS) criteria, ${ }^{8}{ }^{13-15}$ three studies considering vital signs including some SIRS criteria within a structured screening tool ${ }^{16-18}$ and two studies considering EMS provider identification alone ${ }^{12} 19$ (table 2). The primary vital signs considered in seven studies were temperature, heart rate and RR. Additional, clinically relevant criteria considered included systolic or mean arterial BP $(n=5)$, GCS $(n=3)$, oxygen saturation $(n=2)$, blood glucose level $(n=1)$, in-hospital lactate $(n=1)$, or abnormal in-hospital white blood cell count $(n=1)$. ED physician diagnosis of sepsis indicated by ED charting or the International Statistical Classification of Diseases and related health problems (ICD) codes for sepsis or infection were the most commonly used reference standard for the definitive diagnosis of sepsis (eight of nine studies).

\section{Sensitivity and specificity of prehospital sepsis identification}

There was considerable variation in the calculated sensitivity for EMS identification of sepsis and the index tests that were applied to recognise sepsis (table 2). Variability in the criteria considered and parameters for classifying these criteria as abnormal (eg, RR >20 vs RR >36) limited our ability to perform a meta-analysis (figure 2). EMS provider impression alone was investigated in six studies, with five studies describing very poor sensitivity (0.1-0.31) and one describing modest sensitivity 
Table 1 Characteristics of included studies

\begin{tabular}{|c|c|c|c|c|c|c|c|}
\hline Study & Purpose & Design & $\begin{array}{l}\text { Study } \\
\text { country }\end{array}$ & $\begin{array}{l}\text { Number of } \\
\text { centres }\end{array}$ & $\begin{array}{l}\text { Sample } \\
\text { size }\end{array}$ & $\begin{array}{l}\text { Reported } \\
\text { incidence }\end{array}$ & GRADE \\
\hline \multicolumn{8}{|c|}{ Studies describing the identification of sepsis by EMS providers } \\
\hline $\begin{array}{l}\text { Asayama and } \\
\text { Aikawa }^{13}\end{array}$ & To evaluate SIRS criteria as a predictor of mortality & $\begin{array}{l}\text { Retrospective } \\
\text { cohort }\end{array}$ & Japan & 1 Hospital & 59 Patients & $59 / 2180 ; 2.7 \%$ & Low \\
\hline Bayer et al ${ }^{18}$ & $\begin{array}{l}\text { To develop and evaluate an early sepsis detection tool for } \\
\text { EMS }\end{array}$ & $\begin{array}{l}\text { Retrospective } \\
\text { cohort }\end{array}$ & Germany & 1 Hospital & 375 Patients & $\begin{array}{l}375 / 14399 ; \\
2.6 \%\end{array}$ & Moderate \\
\hline $\begin{array}{l}\text { Groenewoudt } \\
\text { et } a l^{19}\end{array}$ & $\begin{array}{l}\text { To describe patients transported by EMS and } \\
\text { their management by EMS providers }\end{array}$ & $\begin{array}{l}\text { Retrospective } \\
\text { cohort }\end{array}$ & Netherlands & 1 Hospital & 287 Patients & Not available & Moderate \\
\hline Guerra et al ${ }^{14}$ & $\begin{array}{l}\text { To evaluate EMS provider identification of severe sepsis } \\
\text { using a screening tool }\end{array}$ & $\begin{array}{l}\text { Prospective } \\
\text { cohort }\end{array}$ & USA & 3 Hospitals & 112 Patients & $\begin{array}{l}112 / 15538 \\
0.7 \%\end{array}$ & Low \\
\hline Polito et $a l^{17}$ & $\begin{array}{l}\text { To develop an EMS screening tool for identifying severe } \\
\text { sepsis }\end{array}$ & $\begin{array}{l}\text { Retrospective } \\
\text { cohort }\end{array}$ & USA & 1 Hospital & 555 Patients & $75 / 555 ; 14 \%$ * & Low \\
\hline Seymour et $a l^{8}$ & $\begin{array}{l}\text { To describe the incidence of severe sepsis seen in the } \\
\text { prehospital setting }\end{array}$ & $\begin{array}{l}\text { Retrospective } \\
\text { cohort }\end{array}$ & USA & Not described & $\begin{array}{l}13249 \\
\text { Patients }\end{array}$ & $\begin{array}{l}13249 / \\
540351 ; 2.5 \%\end{array}$ & Moderate \\
\hline Studnek et $a l^{12}$ & $\begin{array}{l}\text { To determine the effect of prehospital treatment on the } \\
\text { time to definitive sepsis treatment }\end{array}$ & $\begin{array}{l}\text { Prospective } \\
\text { cohort }\end{array}$ & USA & 1 Hospital & 311 Patients & Not available & Low \\
\hline Suffoletto et al ${ }^{15}$ & $\begin{array}{l}\text { To evaluate EMS provider impression and physiological } \\
\text { measures on the identification of patients with severe } \\
\text { infection }\end{array}$ & $\begin{array}{l}\text { Prospective } \\
\text { cohort }\end{array}$ & USA & 1 Hospital & $\begin{array}{l}201 \text { EMS } \\
\text { providers }\end{array}$ & $16 / 199 ; 8 \%$ & Very low \\
\hline Wallgren et $a l^{16}$ & $\begin{array}{l}\text { To validate prehospital screening tools for sepsis against } \\
\text { provider impression }\end{array}$ & $\begin{array}{l}\text { Retrospective } \\
\text { cohort }\end{array}$ & Sweden & 1 Hospital & 353 Patients & Not available & Very low \\
\hline \multicolumn{8}{|c|}{ Studies describing EMS care delivery of patients with sepsis } \\
\hline Baez et a ${ }^{23}$ & $\begin{array}{l}\text { To assess the predictive effect of prehospital physiological } \\
\text { measures on patient outcome }\end{array}$ & $\begin{array}{l}\text { Retrospective } \\
\text { cohort }\end{array}$ & USA & 1 Hospital & 63 Patients & Not available & Very low \\
\hline Band et $a^{24}$ & $\begin{array}{l}\text { To assess time to treatment for patients arriving with } \\
\text { EMS }\end{array}$ & $\begin{array}{l}\text { Prospective } \\
\text { cohort }\end{array}$ & USA & 1 Hospital & 963 Patients & Not available & Moderate \\
\hline Femling et $a l^{25}$ & $\begin{array}{l}\text { To describe patients transported by EMS and their } \\
\text { subsequent ED management and outcomes }\end{array}$ & $\begin{array}{l}\text { Retrospective } \\
\text { cohort }\end{array}$ & USA & 6 Hospitals & 485 Patients & Not available & Low \\
\hline $\begin{array}{l}\text { Seymour } \\
\text { et } a^{21} 22\end{array}$ & $\begin{array}{l}\text { To determine the impact of prehospital fluid resuscitation } \\
\text { on time to achieve resuscitation goals }\end{array}$ & $\begin{array}{l}\text { Retrospective } \\
\text { cohort }\end{array}$ & USA & 1 Hospital & 52 Patients & Not available & Low \\
\hline $\begin{array}{l}\text { Seymour } \\
\text { et } a^{21} 22\end{array}$ & $\begin{array}{l}\text { To describe patient characteristics and EMS care of } \\
\text { patients }\end{array}$ & $\begin{array}{l}\text { Retrospective } \\
\text { cohort }\end{array}$ & USA & 1 Hospital & 216 Patients & Not available & Low \\
\hline Seymour et $a l^{20}$ & $\begin{array}{l}\text { To describe the impact of EMS fluid resuscitation on } \\
\text { patient mortality }\end{array}$ & $\begin{array}{l}\text { Prospective } \\
\text { cohort }\end{array}$ & USA & 15 Hospitals & $\begin{array}{l}1350 \\
\text { Patients }\end{array}$ & $\begin{array}{l}1450 / 45394 \\
3.2 \%\end{array}$ & Moderate \\
\hline Wang et $a l^{11}$ & To describe patient characteristics & $\begin{array}{l}\text { Prospective } \\
\text { cohort }\end{array}$ & USA & 1 Hospital & $\begin{array}{l}1576 \\
\text { Patients }\end{array}$ & Not available & Low \\
\hline
\end{tabular}

${ }^{*}$ Total patient population restricted to exclude patients unlikely to have sepsis during EMS care (ex. Trauma, Cardiac arrest).

ED, emergency department; EMS, emergency medical services; GRADE, Grading of Recommendations Assessment, Development and Assessment; SIRS, systemic inflammatory response syndrome.

(0.63) (table 2). Three structured screening tools developed using EMS data were described with high sensitivity (0.75-0.87) and moderate specificity $(0.47-0.87){ }^{16-18}$ Applying SIRS criteria and EMS provider impression together was only explicitly investigated by one study with a moderate sensitivity and specificity $(0.50,0.83$; table 2$) .^{15}$

\section{Prehospital management}

Our search identified no randomised controlled trials or interventional studies of EMS treatments of sepsis. The specific treatments delivered by EMS providers were described in three cohort studies (table 3); these focused on maintenance of BP through fluid administration, with time to achieve BP targets, or overall mortality as the outcomes. ${ }^{20-22}$ The remaining cohort studies included $(n=5)$ described general management approaches, transfer characteristics or potential prehospital predictors of patient outcome (table 3). ${ }^{11} 19{ }^{23-25}$ EMS provider management of patients with sepsis was associated with extended on-scene times (one study, mean $43 \mathrm{~min}$ ). ${ }^{8}$ Patients who received intravenous fluids from the EMS during this time, however, had significant reductions in their odds of death according to one cohort study $(\mathrm{OR}=0.46 ; 95 \%$ CI 0.23 to
0.88). ${ }^{20}$ Notably, three studies reported that only limited support of BP by EMS providers (in $<50 \%$ of these patients) occurred despite the measurement and documentation of hypotension. ${ }^{20-22}$ The variability in studied treatment strategies and limited number of studies precluded any formal meta-analysis.

\section{DISCUSSION}

We conducted a comprehensive and systematic review of the available literature describing prehospital identification or management of patients with sepsis and retrieved only observational studies and no randomised controlled trials. Our review shows that sepsis is a common condition for EMS patients, with an estimated incidence ranging from $1 \%$ to $8 \%$ among EMS-transported patients. However, only a few studies of moderate quality have evaluated the accuracy of prehospital identification of sepsis, and randomised controlled trials describing potential treatment strategies are lacking.

Our review provides the first comprehensive review of the identification and management of patients with sepsis by EMS providers in the prehospital setting. The most common approaches applied by EMS providers to identify sepsis are a variation of SIRS criteria or screening tools that include aspects 
Table 2 Emergency medical services identification of sepsis

\begin{tabular}{|c|c|c|c|c|}
\hline Study & Predictor(s) evaluated & Reference standard & Sensitivity $(95 \% \mathrm{CI})$ & Specificity $(95 \% \mathrm{CI})$ \\
\hline $\begin{array}{l}\text { Asayama and } \\
\text { Aikawa }^{13}\end{array}$ & $\begin{array}{l}\text { SIRS }(T>38 \text { or }<36, H R>90, R R>20, W B C<4000 \text { or } \\
>12000)\end{array}$ & Treatment for infection & $0.73(0.60$ to 0.84$)$ & $0.87(0.86$ to 0.89$)$ \\
\hline Bayer et $a l^{18}$ & $\begin{array}{l}\text { Vital signs ( } \mathrm{T}>38 \text { or }<36, \mathrm{pCO}_{2}<4.3 \mathrm{kPa}, \mathrm{HR}>90 \text {, } \\
\mathrm{RR}>22, \mathrm{WBC} \text { ) PRESEP score }\end{array}$ & $\begin{array}{l}\text { Dual MD consensus } \\
\text { on diagnosis }\end{array}$ & $\begin{array}{l}\text { PRESEP score: } 0.85 \text { (0.76 to } \\
0.92)\end{array}$ & $\begin{array}{l}\text { PRESEP Score* }{ }^{*} 0.86(0.82 \text { to } \\
0.90)\end{array}$ \\
\hline $\begin{array}{l}\text { Groenewoudt } \\
\text { et }\left.a\right|^{19}\end{array}$ & Provider impression & MD diagnosis in ED & $0.63(0.58$ to 0.69$)$ & Unable to calculate \\
\hline Guerra et $a l^{14}$ & $\begin{array}{l}\text { Sepsis alert protocol (T }>38 \text { or }<36, H R>90, R R>20 \text {, } \\
\text { WBC }<4000 \text { or }>12000, S B P<90, M A P<65 \text {, lactate } \geq 4 \text { ) } \\
\text { Provider impression }\end{array}$ & $\begin{array}{l}\text { ICD-9 for infection } \\
\text { plus } 2 \text { SIRS }\end{array}$ & $\begin{array}{l}\text { Sepsis alert protocol: } 0.48 \\
\text { (0.35 to } 0.60) \\
\text { Provider impression: } 0.10 \\
\text { (0.03 to } 0.22 \text { ) }\end{array}$ & Unable to calculate \\
\hline Polito et al ${ }^{17}$ & Vital signs (HR>90, RR $>20), S B P<110$, PRESS score & $\begin{array}{l}\text { MD diagnosis within } \\
48 \mathrm{~h}\end{array}$ & $\begin{array}{l}\text { PRESS score: } 0.87 \text { ( } 0.77 \text { to } \\
0.93) \\
\text { Provider impression: } 0.19 \\
(0.11 \text { to } 0.29)\end{array}$ & $\begin{array}{l}\text { PRESS Score }{ }^{*}: 0.43(0.39 \text { to } \\
0.48) \\
\text { Provider Impression: Unable to } \\
\text { Calculate }\end{array}$ \\
\hline Seymour et $a l^{8}$ & $\begin{array}{l}\text { Vital signs }\left(S B P \leq 90, R R>36, G C S \leq 11, S O_{2}<88\right. \\
H R \geq 120)\end{array}$ & $\begin{array}{l}\text { MD diagnosis with } \\
\text { lactate measured }\end{array}$ & $\begin{array}{l}\text { SBP: } 0.19(0.18 \text { to } 0.19) \\
\text { RR: } 0.14(0.13 \text { to } 0.14) \\
\text { GCS: } 0.13(0.12 \text { to } 0.13) \\
\mathrm{SpO}_{2}: 0.10(0.10 \text { to } 0.11) \\
\text { HR: } 0.21(0.20 \text { to } 0.22)\end{array}$ & Unable to calculate \\
\hline Studnek et $a l^{12}$ & Provider impression & MD diagnosis in ED & $0.21(0.15$ to 0.28$)$ & Unable to calculate \\
\hline Suffoletto et al ${ }^{15}$ & $\begin{array}{l}\text { Vital signs }\left(H R>90, R R>20, S B P<100, S_{2} O_{2}<95\right) \\
\text { Presence of fever } \\
\text { Provider impression }\end{array}$ & MD diagnosis in ED & $\begin{array}{l}\text { Vital signs } \uparrow+\text { provider } \\
\text { impression: } 0.50(0.32 \text { to } 0.68) \\
\text { SBP: } 0.28(0.14 \text { to } 0.47) \\
\text { Fever: } 0.25(0.12 \text { to } 0.43) \\
\text { Provider impression: } 0.31 \\
(0.16 \text { to } 0.50)\end{array}$ & $\begin{array}{l}\text { Vital signs }++ \text { Provider Impression: } \\
0.83(0.77 \text { to } 0.88) \\
\text { SBP: } 0.88 \text { ( } 0.82 \text { to } 0.93) \\
\text { Fever: } 0.95 \text { ( } 0.90 \text { to } 0.98) \\
\text { Provider Impression: } 0.93(0.88 \\
\text { to } 0.96)\end{array}$ \\
\hline Wallgren et $a l^{16}$ & $\begin{array}{l}\text { Robson tool: (T>38.3 or }<36, \mathrm{HR}>90, \mathrm{RR}>20, \text { Acute } \\
\text { altered } \mathrm{LOC} \text {, glucose }>6.6 \mathrm{mmol} / \mathrm{L}) \\
\text { BAS tool: }\left(\mathrm{SBP}<90, \mathrm{RR}>30, \mathrm{SpO}_{2}<90\right) \\
\text { Provider impression }\end{array}$ & ICD-9 for sepsis & $\begin{array}{l}\text { Robson tool: } 0.75 \text { ( } 0.53 \text { to } \\
0.90) \\
\text { BAS tool: } 0.43 \text { ( } 0.36 \text { to } 0.51) \\
\text { Provider impression: } 0.11 \\
(0.08 \text { to } 0.14)\end{array}$ & Unable to calculate \\
\hline
\end{tabular}

of SIRS. Our findings suggest that EMS providers' abilities to correctly identify this condition vary considerably depending on the criteria used, but use of a structured screening strategy, such as a tool, has much better accuracy than provider impression alone. Our review also highlights the need for the validation of prehospital sepsis screening strategies with improved sensitivity and specificity for recognition of sepsis and to ensure that prehospital screening for sepsis does not result in harm (ie, inappropriate treatment).

Although few studies have demonstrated an association between early EMS recognition or treatment of sepsis and improved patient outcomes, we identified several studies that show earlier initiation of treatment within the ED and a trend towards earlier achievement of resuscitation goals (table 3). Despite shorter transport times in some urban settings, EMS providers are often the first contact for these patients with a health professional, who remains with them throughout the transport and transfer of care to hospital staff. This offers an important opportunity for early recognition and notification of emergency staff and for the initiation of treatments in the prehospital setting. Further study examining a larger population of patients from settings where transport times vary may demonstrate a greater benefit for EMS recognition and treatment of this disease.

Fluid resuscitation of patients with sepsis by EMS providers was the most commonly described intervention and was
Figure 2 Sensitivity and specificity of emergency medical services (EMS) identification of sepsis using vital signs, or provider impression alone. ${ }^{12-19} \mathrm{FN}$, false negative; FP, false positive; SIRS, systemic inflammatory response syndrome; TN, true negative; TP, true positive.

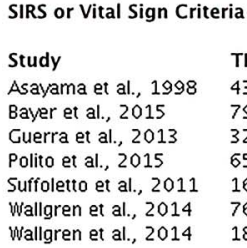

SIRS or Vital Sign Criteria

Study

Asayama et al., 1998 Bayer et al., 2015 Guerra et al., 2013 Polito et al., 2015 Suffoletto et al., 2011 Wallgren et al., 2014 Wallgren et al., 2014

EMS Provider Identification

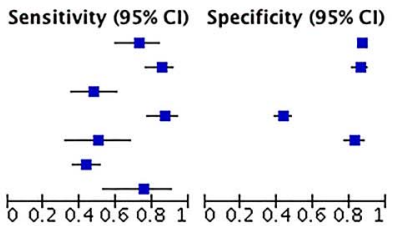

Study

Groenewoudt et al., 2014

Guerra et al., 2013

Polito et al., 2015

Studnek et al., 2012

Suffoletto et al., 2011

Wallgren et al., 2014 
Table 3 EMS provider management of patients with sepsis

\begin{tabular}{|c|c|c|c|}
\hline Study & Measures evaluated & Outcomes measured (results) & Key findings \\
\hline Baez et $a l^{23}$ & T, HR, MAP, RR, SI, glucose & $\begin{array}{l}\text { ICU admission (68\%), mortality (35\%), mean } \\
\text { ventilator days (4.93), ICU days (7) }\end{array}$ & $\begin{array}{l}\text { Abnormal prehospital SI (HR/SBP) and RR predict ICU admission. No } \\
\text { correlation to mortality }\end{array}$ \\
\hline Band et $a l^{24}$ & $\begin{array}{l}\text { Time to initial } A B \\
\text { administration, time to initial } \\
\text { IVF administration }\end{array}$ & $\begin{array}{l}\text { Time to initial ABs ( } 116 \text { vs } 152 \mathrm{~min} \text { ) } \\
\text { Time to initial IVF ( } 34 \text { vs } 68 \mathrm{~min} \text { ) } \\
\text { Adjusted relative risk for mortality (1.24 vs } \\
\text { 1.66; NS) }\end{array}$ & $\begin{array}{l}\text { Arrival in the emergency department by EMS shortens time to } \\
\text { initiation of } A B \text { and IVF }\end{array}$ \\
\hline Femling et $a l^{25}$ & $\begin{array}{l}\text { Characteristics of EMS patients } \\
\text { with sepsis compared with } \\
\text { walk-in patients }\end{array}$ & $\begin{array}{l}\text { Described EMS patient characteristics. } \\
\text { Time to ABs was shorter for EMS patients ( } 87 \\
\text { vs } 120 \text { min, } p=0.02 \text { ) } \\
\text { Impact of EMS interventions (transport, total } \\
\text { fluid given) on mortality (NS) }\end{array}$ & $\begin{array}{l}\text { EMS patients were older, had more severe illness and met more SIRS } \\
\text { on arrival } \\
\text { EMS transport decreased time to ABs } \\
\text { EMS interventions showed no association with decreased patient } \\
\text { mortality }\end{array}$ \\
\hline $\begin{array}{l}\text { Groenewoudt } \\
\text { et } a l^{19}\end{array}$ & $\begin{array}{l}\text { Characteristics of EMS patients } \\
\text { with sepsis, EMS provider } \\
\text { documentation of sepsis }\end{array}$ & $\begin{array}{l}\text { EMS patient severity of illness and mortality, } \\
\text { EMS provider management }\end{array}$ & $\begin{array}{l}\text { Nearly half of septic patients arrive in the emergency department by } \\
\text { EMS, most were not considered urgent transports, routine vital signs } \\
\text { intervention was not seen }\end{array}$ \\
\hline $\begin{array}{l}\text { Seymour } \\
\text { et } a l^{2122}\end{array}$ & $\begin{array}{l}\text { Receiving prehospital fluid, } \\
\text { patients for whom resuscitation } \\
\text { goals were achieved within } 6 \mathrm{~h}\end{array}$ & $\begin{array}{l}\text { Prehospital receipt of IVF ( } 48 \%) \\
M A P \geq 65 \mathrm{~mm} \mathrm{Hg} \text { achieved ( } 70 \% \text { vs } 44 \% ; \mathrm{NS}) \\
\left.\mathrm{CVP} \geq 8 \mathrm{~cm} \mathrm{H} \mathrm{H}_{2} \mathrm{O} \text { achieved ( } 72 \% \text { vs } 60 \% ; \mathrm{NS}\right) \\
\left.\mathrm{S}_{\mathrm{CV}} \mathrm{O}_{2} \geq 70 \% \text { achieved ( } 54 \% \text { vs } 36 \% ; \mathrm{NS}\right)\end{array}$ & $\begin{array}{l}\text { Less than half of patients with severe sepsis received IVF by EMS } \\
\text { Prehospital receipt of IVF shows a trend towards significant } \\
\text { improvement in achieving EGDT goals by } 6 \mathrm{~h}\end{array}$ \\
\hline $\begin{array}{l}\text { Seymour } \\
\text { et }\left.a\right|^{2122}\end{array}$ & $\begin{array}{l}\mathrm{SBP}, \mathrm{HR}, \mathrm{GCS}, \mathrm{RR}, \mathrm{SpO}_{2} \\
\text { delivery of IVF }\end{array}$ & $\begin{array}{l}\text { Abnormal measures associated with increased } \\
\text { serum lactate }\left(\mathrm{SBP}, \mathrm{GCS}, \mathrm{SpO}_{2}\right) \\
\text { Abnormal measures associated with increased } \\
\left.\text { SOFA score (SBP, GCS, } \mathrm{RR}, \mathrm{SpO}_{2}\right) \\
\text { Patients who received fluid in shock }(38 \%)\end{array}$ & $\begin{array}{l}\text { Routine prehospital-measured clinical variables are associated with } \\
\text { increased serum lactate and SOFA scores. } \\
\text { Less than half of patients with severe sepsis received IVF by EMS } \\
\text { Mortality of EMS patient with sepsis }(24 \%)\end{array}$ \\
\hline Seymour et $a l^{20}$ & $\begin{array}{l}\text { Venous catheter placement by } \\
\text { EMS, IVF resuscitation by EMS }\end{array}$ & Mortality, organ failures, ICU admission & $\begin{array}{l}\text { Venous catheter placement odds of death (OR=0.3, } 95 \% \mathrm{Cl} 0.17 \text { to } \\
0.57 \text { ) } \\
\text { IVF administration odds of death (OR=0.46,95\% Cl } 0.23 \text { to } 0.88 \text { ) }\end{array}$ \\
\hline Wang et $a l^{11}$ & $\begin{array}{l}\text { Characteristics of EMS patients } \\
\text { with sepsis }\end{array}$ & $\begin{array}{l}\text { Patients with sepsis transported by EMS }(34 \%) \\
\text { Odds of initial EMS care of patients with severe } \\
\text { sepsis (3.9) and patients with septic shock (3.6) } \\
\text { Adjusted mortality in EMS patients (OR=1.8) }\end{array}$ & $\begin{array}{l}\text { EMS initially cares for large proportion of patients with sepsis } \\
\text { EMS initially cares for more patients with severe sepsis and more } \\
\text { patients with septic shock }\end{array}$ \\
\hline
\end{tabular}

reported to reduce the time to achieving BP goals for these patients after hospital arrival and decrease their odds of death. $^{20} 22$ Despite this finding, only a small fraction of these patients were fluid resuscitated by EMS providers, often $<50 \%$ of patients with severe sepsis (table 3). However, these studies often lacked comparison groups, or were vulnerable to a risk of confounding by indication and selection bias. Further investigation with randomised controlled trials is required.

Our study has several limitations. Despite our comprehensive literature search, we were unable to find studies of high methodological quality evaluating EMS identification. Notably, retrieved studies were characterised by a risk of selection bias as many had restrictive inclusion criteria and identified patients retrospectively. Another limitation of the studies included was a lack of systematic screening of patients transported by EMS, which precluded estimation of specificity and false negative rates for prehospital sepsis diagnosis for many studies. This limitation was partially because the objectives of the studies identified did not align with the objective of this review. We excluded conference abstracts and non-English studies, leaving a potential gap in our understanding of the emerging research for this area; however, we feel it is unlikely that significant advances in the science of prehospital sepsis treatment were missed. Most of the studies included were conducted in the USA, which may limit the generalisability of our findings to other prehospital systems of care. Finally, future research exploring the accuracy of prehospital identification should strive to include a complete and representative sample of all EMS-transported patients to reduce the risk for selection bias.

\section{CONCLUSION}

In summary, EMS providers will commonly encounter patients with severe sepsis when responding in the prehospital setting. However, the available evidence suggests that the identification of sepsis by EMS providers is done with varied success, depending on the strategy used. Relying on provider impression alone had limited success, whereas applying a structured screening strategy showed reasonable success. However, only a few studies of moderate quality have assessed the ability of EMS providers to identify patients with sepsis, and treatments have seldom been explored. Additional research to improve diagnostic accuracy and explore improvements in EMS management is needed.

Twitter Follow Daniel Lane at @danlane911

Contributors All authors were integral in the conception of this work and the acquisition, analysis and interpretation of data. All authors contributed to the draft and review of this work and reviewed the final version. The authors agree to be accountable for all aspects of the work in ensuring that questions related to the accuracy or integrity of any part of the work are appropriately investigated and resolved.

Competing interests None declared.

Provenance and peer review Not commissioned; externally peer reviewed.

\section{REFERENCES}

1 Vincent JL, Rello J, Marshall J, et al. International study of the prevalence and outcomes of infection in intensive care units. JAMA 2009;302:2323-9.

2 Dellinger RP, Levy MM, Rhodes A, et al. Surviving sepsis campaign: international guidelines for management of severe sepsis and septic shock, 2012. Intensive Care Med 2013;39:165-228. 
3 Yealy DM, Kellum JA, Huang DT, et al., ProCESS Investigators. A randomized trial of protocol-based care for early septic shock. N Engl J Med 2014;370:1683-93.

4 Kumar A, Roberts D, Wood KE, et al. Duration of hypotension before initiation of effective antimicrobial therapy is the critical determinant of survival in human septic shock. Crit Care Med 2006;34:1589-96.

5 Iwami T, Nichol G, Hiraide A, et al. Continuous improvements in 'chain of survival' increased survival after out-of-hospital cardiac arrests a large-scale population-based study. Circulation 2009;119:728-34.

6 Stiell IG, Nesbitt LP, Pickett W, et al. The OPALS Major Trauma Study: impact of advanced life-support on survival and morbidity. CMAJ 2008;178:1141-52.

7 Minnerup J, Wersching $\mathrm{H}$, Unrath $\mathrm{M}$, et al. Effects of emergency medical service transport on acute stroke care. Eur J Neurol 2014;21:1344-7.

8 Seymour CW, Rea TD, Kahn JM, et al. Severe sepsis in pre-hospital emergency care. Am J Respir Crit Care Med 2012;186:1264-71.

9 Herlitz J, Bång A, Wireklint-Sundström B, et al. Suspicion and treatment of severe sepsis. An overview of the prehospital chain of care. Scand I Trauma Resusc Emerg Med 2012;20:42.

10 Schünemann HJ, Oxman AD, Brozek J, et al. GRADE: grading quality of evidence and strength of recommendations for diagnostic tests and strategies. BMJ 2008;336:1106.

11 Wang HE, Weaver MD, Shapiro NI, et al. Opportunities for emergency medical services care of sepsis. Resuscitation 2010;81:193-7.

12 Studnek JR, Artho MR, Garner CL Jr, et al. The impact of emergency medical services on the ED care of severe sepsis. Am J Emerg Med 2012;30:51-6.

13 Asayama K, Aikawa N. Evaluation of systemic inflammatory response syndrome criteria as a predictor of mortality in emergency patients transported by ambulance. Keio J Med 1998;47:19-27.

14 Guerra WF, Mayfield, TR, Meyers MS, et al. Early detection and treatment of patients with severe sepsis by prehospital personnel. J Emerg Med 2013;44:1116-25.
15 Suffoletto $B$, Frisch A, Prabhu A, et al. Prediction of serious infection during prehospital emergency care. Prehosp Emerg Care 2011;15:325-30.

16 Wallgren UM, Castrén M, Svensson AEV, et al. Identification of adult septic patients in the prehospital setting. Eur J Emerg Med 2014;21:260-5.

17 Polito CC, Isakov A, Yancey AH, et al. Prehospital recognition of severe sepsis: development and validation of a novel emergency medical services screening tool. Am J Emerg Med 2015;33:1119-25.

18 Bayer 0 , Schwarzkopf D, Stumme $C$, et al. An early warning scoring system to identify septic patients in the prehospital setting: the PRESEP score. Acad Emerg Med 2015;22:868-71.

19 Groenewoudt M, Roest AA, Leijten FMM, et al. Septic patients arriving with emergency medical services: a seriously ill population. Eur J Emerg Med 2014:21:330-5.

20 Seymour CW, Cooke CR, Heckbert SR, et al. Prehospital intravenous access and fluid resuscitation in severe sepsis: an observational cohort study. Crit Care 2014; 18:533

21 Seymour CW, Band RA, Cooke CR, et al. Out-of-hospital characteristics and care of patients with severe sepsis: a cohort study. J Crit Care 2010;25:553-62.

22 Seymour CW, Cooke CR, Mikkelsen ME, et al. Out-of-hospital fluid in severe sepsis: effect on early resuscitation in the emergency department. Prehosp Emerg Care 2010;14:145-52

23 Baez AA, Hanudel P, Wilcox SR. The prehospital sepsis project: out-of-hospital physiologic predictors of sepsis outcomes. Prehosp Disaster Med 2013;28:632-5.

24 Band RA, Gaieski DF, Hylton JH, et al. Arriving by emergency medical services improves time to treatment endpoints for patients with severe sepsis or septic shock. Acad Emerg Med 2011;18:934-40.

25 Femling J, Weiss S, Hauswald E, et al. EMS patients and walk-in patients presenting with severe sepsis: differences in management and outcome. South Med J 2014; 107:751-6. 